\title{
Laboratory programming languages and standardization
}

\section{N. JOHN CASTELLAN, JR.*, Symposium Discussant Indiana Lnilersity, Bloomington, Indiana 47405}

As one reviews the five languages presented at this symposium, one is struck by several things. First of all. the languages are quite general within the context of experimentation and are fairly powerful experimental descriptors. Secondly, although there are differences among them, they are all fairly clear, even to those who are not acquainted with them. Finally, they are each the result of many man-years of experience with real-time experimental control-this is in addition to the man-months of effort required to develop them. Before going on to discuss some more critical aspects of real-time experimental programming languages, I would like to summarize briefly some of the similarities and differences between the various languages presented. These characteristics include language structure, time-sharing characteristics, intermediate conversion, transportability, and several criteria concerning the power of the language in various contexts. The criteria include generality, core use efficiency, simplicity of $\mathrm{I} / \mathrm{O}$ operations, and the ease of use or user orientation of the language. Some of these criteria grew out of an NSF computer science training session held at the University of Colorado. The summary is contained in Table 1 .

Although laboratory automation has been accomplished by means of the use of digital computers for the last 10-15 years, it is only during the last 3 to 5 years that some research laboratories have directed special attention towards the development of special-purpose programming languages for laboratory automation and process control. There are several reasons for this interest. It is, in part, due to the fact that one finds greater shared use of facilities within an institution and rapidly changing experimental paradigms used by researchers having access to a computer. Moreover, the need (or at least desire) to rapidly change and alter experimental procedures has encouraged researchers to develop special languages to facilitate the computer programming tasks associated with their research projects. Another development which has hastened the development of special languages has been the changes in hardware design coupled with large reductions in the cost of core memories.

The languages presented in this symposium are distinguished from earlier efforts by two important characteristics. First. these languages have been developed by psychologists who are also sophisticated

\footnotetext{
*The remarks in this paper are based upon the prepared discussion of the symposium by the author. Subsequent to the symposium, these comments were revised to reflect the substance of the remarks offered from the floor.
}

computer scientists. Second, these languages have been implemented and have been used in a variety of experimental situations.

As one views the languages and sees their descriptive power, the question of ease of implementation arises. The question of implementation is a complicated one since one finds different syntax as one moves from language to language, and the terminology of one language may be very different from that of another. One does find, however, a fairly clear and consistent understanding of the functions to be performed in experimental control. It should be noted also that the languages do differ in the manner in which the $E$ is freed from bookkeeping chores. One gets the impression that it is indeed desirable that, if good general languages are to be developed, there must be some communication between those developing such languages and there must be some agreement concerning terminology for certain functions.

However, the need for standardized terminology takes a different and greater meaning when one considers that laboratory automation and process control in general is a very big and varied business. In fact, the problems of the behavioral scientist in digital control is only a small part of the tip of a very large iceberg.

\section{THE MOVEMENT TOWARDS STANDARDS IN PROCESS CONTROL LANGUAGES}

For some time, the industrial users of computers for process control have recognized the need for standardization of languages for control systems. While the needs for such standardization are many, the important reasons-from the industrial viewpoint-can be reduced to economic ones. First, standardization of languages can facilitate the procurement of software (and hardware), ease the programming burden, and enhance and improve installation management. Second, the training of programmers and technicians can be facilitated by permitting specialized training courses to be developed and process emulators and simulators to be implemented on large machines. Third, successful standardization would make programs interchangeable and transportable so that the same control program could be implemented on any machine. These are also the needs of the behavioral sientist.

Such considerations. coupled with the proliferation of special-purpose control languages in industry, led the Instrument Society of America to establish a series of "workshops" on the standardization of industrial control languages in conjunction with the Laboratory for Applied Industrial Control at Purdue University. 1 These workshops have been held twice each year since 1969. and an impressive amount of work has been done 


\begin{tabular}{|c|c|c|c|c|c|}
\hline & $\begin{array}{l}\text { Extended } \\
\text { SCAT }\end{array}$ & GEPS & PROSS & PSYCHOL & APCOL \\
\hline $\begin{array}{l}\text { Organization } \\
\text { of Language }\end{array}$ & $\begin{array}{l}\text { States and } \\
\text { Transitions }\end{array}$ & Fortran-Like & Fortran-Like & Algol-Like & PL/L-Like \\
\hline $\begin{array}{l}\text { Imbedded } \\
\text { Language State- } \\
\text { ments Allowed }\end{array}$ & Fortran & Assembler? & Assembler & Assembler & Assembler \\
\hline Time-Sharing & Yes & Partial & Yes & No & Partial \\
\hline $\begin{array}{l}\text { Experimental } \\
\text { Generality }\end{array}$ & Good & Fair & $\begin{array}{l}\text { Awkward for } \\
\text { Complex } \\
\text { Experiments }\end{array}$ & Good & Good \\
\hline I/O Simplicity & $\begin{array}{l}\text { Simple but } \\
\text { Limited }\end{array}$ & Simple & Simple & Fair & Simple \\
\hline User Orientation & $\begin{array}{l}\text { Awkward but } \\
\text { Logically } \\
\text { Powerful }\end{array}$ & $\begin{array}{l}\text { Fair (Useful } \\
\text { Macros) }\end{array}$ & Good & $\begin{array}{l}\text { Fair (Overly } \\
\text { Detailed) }\end{array}$ & Good \\
\hline $\begin{array}{l}\text { Systems } \\
\text { Implemented }\end{array}$ & Sigma 3 & IBM 1800 & IBM 1800 & DDP 116 & DDP $116 /$ Univac 1108 \\
\hline $\begin{array}{l}\text { Potential Trans- } \\
\text { portability }\end{array}$ & Good & Limited & Good & Unknown & Limited \\
\hline
\end{tabular}

in conjunction with industry. Special committees have held additional meetings. The support for these workshops and committees is fairly broad, with support coming from both users and the computer industry. A casual inspection of lists of participants indicates support from IBM, DEC. Control Data, Data General, Honeywell, etc. The workshop also has a representative on the ANSI FORTRAN Standards Committee.

What is the nature of the standardization effort? While there are several continuing workshop committees, three appear to be especially important and have direct relevance to behavioral scientists working in laboratory automation contexts. These are: the FORTRAN Committee, the Long-Term Procedural Language (LTPL) Committee, and the Problem-Oriented Language (POL) Committee. Before discussing each of these efforts, it should be noted that the nature of the standards is directed toward the user. That is, the standards are not addressed specifically to the design of operating systems. since such systems are closely linked to the hardware design of a given system. The standards are intended to be system-transparent and make the assumption that the user knows what sorts of process $I / 0$ are on the particular system and knows the timing resolution or accuracy of that system.

\section{FORTRAN Standards}

In their present state, the FORTRAN standards are addressed to specification of the functional requirements of a control program. That is, the standards suggest that the interrupt handling is done by the system and that a given programmer working on a problem need worry only about what affects his process. Certain job tasking is specified by the standards as well as data types and manipulation, process $1 / O$, and file structures.
For example, as part of task management, the standards specify certain subroutine functions to perform timing functions which may be desired by the programmer. The standards would specify function name, control effect, and associated parameters. Consider the following routines and associated timing functions that have been adopted by the committee.

\section{CALL START $(i, j, k, m)$}

Execute program $i$, after time delay $j$ (with time base $k$ ), return action status $m$ (error flag).

CALL TRNON $(\mathrm{i}, \mathrm{j}, \mathrm{m})$

Execute program $i$, at time of day $j$, return action status m (error flag).

CALL WAIT $(j, k, m)$

Delay execution of next program statement for time $\mathrm{j}$ (with time base $\mathrm{k}$ ), return action status $\mathrm{m}$ (error flag).

Presumably, these routines can handle all of the time-contingent task management required by a process or experiment. (In behavioral research, there would be less need for routine TRNON than for routines START and WAIT.)

A further example concerns process $\mathrm{I} / \mathrm{O}$. The form of analog $\mathrm{I} / \mathrm{O}$ routines has been specified, as has the form of digital I/O routines. All I/O routines are specified in pairs, one form indicating immediate return to the calling routine upon queuing of the $\mathrm{I} / \mathrm{O}$ and the other specifying no return to the calling program until the $\mathrm{I} / \mathrm{O}$ operation is complete.

The other aspects of the FORTRAN standards work concerns standard terminology for bit string and shift operations. and standards for handling random unformatted files. It should be remarked that at least 
one software vendor has implemented many of the suggested standards in their real-time operating system.

\section{Long-Term Procedural Language (LTPL)}

The goal of the LTPL committee is to develop a programming language which is suitable for use in all phases of process control. Such a language would include specifications of interrupt handling. basic job tasking, data types and manipulation rules. $I / O$, and all associated tasks, as well as static and/or dynamic program structure. 11 would be a language similar to (or perhaps a subset of) $\mathrm{PL} / 1$. Associated with each machine and/or operating system would be compilers which would generate an appropriate code for control operations in the same manner that FORTRAN does for numerical computations. The LTPL code would be such that a program written in it would compile and run on any machine if the appropriate process $I / O$ were present. While the description and functional operation of the language would be specified, program management and hardware/software linkage would be left to the operating system.

It is intended by the committee that the language be very general, as is ALGOL or $\mathrm{PL} / \mathrm{I}$, and presumably would become the "standard" language provided by vendors of computers and/or operating systems for real-time process control and laboratory automation.

\section{Problem-Oriented Languages (POLS)}

Because of the generality of LTPL and because certain types of control situations suggest special-purpose languages, the workshops have recognized the need for standards for special languages. All of the programming languages presented at this symposium are problem-oriented languages, in that they use terminology and operations which are specific to the control of psychological experiments.

While the standards group recognizes that one cannot standardize a special language, there is strong sentiment that one have the ability to translate a particular POL to the LTPL. In order to accomplish this, efforts are being directed towards the definition of the facility which will allow the generation of POLs which are compatible with the LTPL and which have the same basic structure. To this end. work has been done on the specification of a general problem-oriented language converter and translater (POLCAT). The power of POLCAT and the LTPL is that if the languages of the symposium were all written as POLs, they would all generate a LTPL code which, if the examples of the Sternberg experiment are all correct. would have the same LTPL code. Of course. the programmer-user need not be aware of such conversion-he needs to be concerned only with using that language which best suits his needs. POLs may differ considerably from one another; some may appear to be like ALGOL. while others may be "fill-in-the-blank" types of langauges like RPG

The languages presented here that are conceptually closest in design to POLs are SCAT and PROSS. These both generate code which is then used by a FORTRAN compiler or assembler, respectively. In both cases, the languages generate series of calls to subroutines and the conversion itself need not be system-dependent-just the subroutines which are called.

\section{EFFECTS OF STANDARDS ON THE BEHAVIORAL SCIENTIST}

The movement towards standardization of process control languages should be viewed with guarded enthusiasm by psychological researchers. The enthusiasm is due to the fact that if standardization is successful, greater attention can be directed by the researcher towards getting basic research done. The development of a fairly standard FORTRAN language did much to encourage and facilitate the development and dissemination of sophisticated "package" programs such as BMD, BCTRY, SPSS, MANOVA, and SMIS for use by behavioral scientists. These languages (which might be called data-analytic POLs) freed researchers in many areas of the necessity of developing their own analysis packages. While the analogy is not perfect, if standardization would have a similar effect on process control and laboratory automation, the result would be significant. Perhaps another advantage of standardization is that it might make the description of experimental procedures in research reports more accurate and clear, since they could be stated compactly in a common language.

Another important benefit of standardization is pedagogical. An important task at most behavioral research laboratories is the training of scientists. This training includes both technical training and scientific training in the logic of experimental design and control. It is my belief that standardization will enhance our training programs in that young scientists will be able to concentrate on the scientific aspects of research and will also have readily transportable technical skills that will not have to be developed from basic principles each time they change work environments

On the other hand. the standards as presently formed have certain weaknesses which are in part due to some basic differences in the nature of experimental control and process control. In process control, all interrupts are meaningful in that each requires some specific action by the control program. Thus, the present standards suggest that all inputs must be interrogated and acted upon by the individual program. However, in experimental control. it is often the case that two identical signals at the same intensity which differ only in the time of their occurrence may be considered as noise at one time or as signal at another. and when it is noise the programmer does not want to be bothered with it. Put differently, laboratory control must deal with the $S$ who is rather conscientious about a particular task and the one who bangs away at response keys during intertrial intervals. In a similar fashion. the standards appear to assume 
rather orderly data in that when one data table is tilled one progresses to the next stage of operation. One characteristic of laboratory automation is that the rate of arrival of data at the computer is a random variable. as is the relative proportion of signal and noise. While the same is true of industrial control processes. the distributions of such random variables in laboratory automation would appear to have larger variance.

Another aspect of laboratory automation is that an experimental procedure may be used for a very brief period (i.e., a few days) and then a new procedure is required immediately, whereas in industrial control the same procedure might be used for many months without modification.
On batance. the movement towats standardization should be watched carcfully by psichologists, and at effort should be made to make nur particular needs anc reçuirements for laboratory automation programming languages known. If the languages presented as part of this symposium are any indication. we have coverec much of the ground necessary to achieve usefu stindards.

\section{NOTE}

1. Information concerning the workshops and copies 0 voluminous minutes of the workshops can be obtained fron Theodore J. Williams, Purdue Laboratory for Industrial Control Purdue University, Lafayette, Indiana 47901. 